\title{
Reframing the Opioid Epidemic as a National Emergency
}

Lawrence O. Gostin

Georgetown University, gostin@law.georgetown.edu

James G. Hodge

Arizona State University Sandra Day O'Connor College of Law, james.hodge.1@asu.edu

Sarah A. Noe

University of Pennsylvania Law School, sanoe@asu.edu

This paper can be downloaded free of charge from:

https://scholarship.law.georgetown.edu/facpub/1999

https://ssrn.com/abstract=3024919

JAMA (Online First), Aug. 23, 2017, at E1-E2

This open-access article is brought to you by the Georgetown Law Library. Posted with permission of the author. Follow this and additional works at: https://scholarship.law.georgetown.edu/facpub 


\section{Reframing the Opioid Epidemic as a National Emergency}

\section{Lawrence 0. Gostin. \\ JD \\ O'Neill Institute for National and Global Health Law, \\ Georgetown University Law Center, \\ Washington, DC. \\ James G. Hodge Jr, JD, \\ LLM \\ Center for Public \\ Health Law and Policy, \\ Sandra Day O'Connor \\ College of Law, Arizona \\ State University, \\ Phoenix.}

\section{Sarah A. Noe, BA}

University of

Pennsylvania Law

School, Philadelphia.
Corresponding

Author: Lawrence $\mathrm{O}$.

Gostin, JD,

Georgetown University

Law Center, 600

New Jersey Ave, NW,

McDonough 568 ,

Washington, DC 20001

(gostin@law

.georgetown.edu).
On August 10, 2017, President Trump announced his intention to declare a national emergency following the recommendation of the President's Commission on Combating Drug Addiction and the Opioid Crisis. ${ }^{1}$ Opioid abuse is among the most consequential preventable public health threats facing the nation. More than 600000 deaths have occurred to date, with 180000 more predicted by $2020 .{ }^{2}$ Of the 20.5 million US residents 12 years or older with substance use disorders in 2015, 2 million were addicted to prescription pain relievers. ${ }^{3}$ A declaration of a national emergency authorizes public health powers, mobilizes resources, and facilitates innovative strategies to curb a rapidly escalating public health crisis.

\section{The Opioid Crisis}

Approximately one-third of individuals in the United States report experiencing chronic pain, and many receive prescription opioids such as oxycodone and acetaminophen/hydrocodone. Opioids are among the most heavily prescribed pharmaceuticals, and they are highly

\section{A declaration of a national emergency authorizes public health powers, mobilizes resources, and facilitates innovative strategies to curb a rapidly escalating public health crisis.}

addictive. Eighty percent of new heroin users have previously misused prescription painkillers.

Although effective pain relief is a vital component of modern health care, the public health effects of opioid addiction have escalated sharply. Opioid overdose deaths increased 156\% from 21088 in 2010 to 33091 in 2015, resulting in decreased life expectancy among users. ${ }^{4}$ Overdose deaths among teenagers increased 19\% from 649 in 2014 to 772 in 2015-more than double the rate since $1999 .{ }^{5}$ Highly potent, chemically manufactured opioids (eg, car- and furanyl-fentanyl) available illegally or by mail order-are potentially lethal through unintentional skin absorption, inhalation, incorrect dosing, or lacing with other drugs. ${ }^{6}$

Sharing drug injection equipment can transmit blood-borne infections such as human immunodeficiency virus (HIV) or hepatitis B or C. If current rates of infection continue, the US Centers for Disease Control and Prevention (CDC) estimates that 1 in 23 women and 1 in 36 men who inject drugs will be diagnosed with HIV during their lifetime. ${ }^{7}$ Opioid use also has contributed to an estimated tripling of hepatitis $\mathrm{C}$ infections between 2010 and 2015. The combined economic influence of the opioid epidemic (health care, labor, and criminal justice costs) was estimated at $\$ 92$ billion in 2016 (an increase of $67 \%$ over a decade ago). ${ }^{8}$ Enhanced public health prevention nationally not only would reduce death and morbidity, but would likely also be highly cost-effective.

\section{Expanding Conceptions of Public Health} Emergencies

Modern public health emergency declarations typically focus on rapidly spreading infectious diseases such as West Nile virus (2002), severe acute respiratory syndrome (2003), H1N1 influenza (2009), Ebola virus (2014), and Zika virus (2016). They are also understood to include biosecurity threats such as anthrax (2001) or smallpox. Humanitarian disasters in the United States, such as hurricanes Katrina (2005) and Sandy (2012), have also triggered public health emergency declarations, particularly at the state level.

This traditional model of public health emergencies, however, is beginning to change. In the past decade states and localities have declared emergencies for health crises such as seasonal influenza, lead-contaminated drinking water, and asbestos releases-even domestic violence, food insecurity, and homelessness. As early as 2011, 6 states (Alaska, Arizona, Florida, Massachusetts, Maryland, and Virginia) and several tribal governments (eg, Red Lake Nation, Mashpee Wampanoag Tribe, Leech Lake, Band of Chippewa Indians, White Earth Nation) have already declared public health emergencies in response to the opioid epidemic.

Existing public health strategies are meaningful and necessary, but an emergency declaration could be a turning point for a national surge response. Current response efforts include patient and prescriber surveillance, reduced medical prescribing, and counseling or treatment for persons at risk or already addicted. The US Food and Drug Administration (FDA) and National Institutes of Health urge research and development of less addictive painkillers, while CDC calls for greater physician and pharmacist education to avoid inappropriate prescribing. US Customs and Border Protection agents are working to restrict the flow of illicit opioids, while law enforcement is targeting illicit drug dealers and unethical physicians. Emergency medical technicians and family members are administering life-saving naloxone with fewer liability concerns due to state Good Samaritan laws.

Essential Powers and Resources

An emergency declaration mobilizes powers and resources that are either currently unavailable or mired in 
legal obstacles. The President's Commission recommends legal and policy reforms including the following: better Medicaid coverage for substance use treatment; expanded funding for integrated medication-assisted treatments; medical training in appropriate pain management; and waivers of health information privacy regulations that impede access to complete data on fraudulent prescription practices and those who misuse opioids.

Coordination of public and private strategies would be facilitated by a crisis standard of care supported by substantial funding through federal laws such as the Comprehensive Addiction and Recovery Act and 21st Century Cures Act. Expansion of health insurance coverage via temporary waivers of key provisions of the Affordable Care Act would open greater access to addiction services. A public health emergency declaration could also increase deployment and use of appointed federal or state officials or volunteer health practitioners, especially in resource-strapped rural communities where opioid-related deaths per capita often exceed those in urban areas.

Jails and prisons are another focal point for public health interventions. Significant numbers of prisoners either used opioids in committing their crimes or were incarcerated with an opioidrelated use disorder. Effective interventions would provide expanded treatment to addicted prisoners by overriding Medicaid provisions that terminate benefits for incarcerated populations. Greater use of drug courts that divert opioid users from punitive to therapeutic settings is also essential.

Emergency waivers of federal drug possession or other legal barriers would enable implementation of clean injection equipment programs or facilities, which are under consideration in New York City, Seattle-King County in Washington, and elsewhere. Federal emergency determinations allow FDA to issue emergency use authorizations for unapproved medical products (or different uses of approved products), while hastening efforts to remove dangerous prescription opioids from the market. The Public Readiness and Emergency Preparedness Act, triggered only by a declaration, provides limited immunity to health professionals and pharmaceutical companies distributing or implementing federally approved medical countermeasures, while authorizing federal compensation for injuries.

A Well-Targeted Emergency Declaration of Limited Duration Declaring a national emergency in response to a decades-long, escalating public health crisis raises valid concerns. Principal among these is the potential for more punitive responses focused on incarceration. There is also the concern that an emergency declaration could justify paternalistic interventions that deny rights to affected patients or their caregivers.

Deploying surge powers and resources in response to the opioid epidemic could divert attention from other major national problems such as cancer, diabetes, and cardiovascular disease. It could also set a precedent for framing nearly any major health hazard as a public health emergency even though such declarations were originally conceived as temporary responses to fast-moving epidemics, bioterrorism, or humanitarian disasters.

Still, a federal emergency declaration is warranted by the addictive quality of opioids, substantial increases in opioid abuse and related deaths, potential for continued catastrophic losses of life, and epidemic-like spread of needle-borne infections through social networks. It may have taken years for this epidemic to reach crisis levels, but it could take only months for coordinated, bipartisan interventions across public and private sectors to take hold. Preventable deaths and injuries attributable to opioid misuse will never be acceptable, but the emergency should come to an end when opioid addiction and death rates return to historic lower levels.

\section{ARTICLE INFORMATION}

Published Online: August 23, 2017.

doi:10.1001/jama.2017.13358

Conflict of Interest Disclosures: All authors have completed and submitted the ICMJE Form for Disclosure of Potential Conflicts of Interest and none were reported.

\section{REFERENCES}

1. President's Commission on Combating Drug Addiction and the Opioid Crisis. Interim Report. Washington, DC; 2017. https://www.whitehouse.gov /ondcp/presidents-commission.
2. Blau M. Opioids could kill nearly 500,000 Americans in the next decade. https://www .statnews.com/2017/06/27/opioid-deaths -forecast/. June 27, 2017. Accessed August 16, 2017.

3. American Society of Addiction Medicine. Opioid Addiction 2016 Facts and Figures. Washington, DC: American Society of Addiction Medicine; 2016.

4. National Institutes of Health, National Institute of Drug Abuse. Overdose death rates. https://www .drugabuse.gov/related-topics/trends-statistics /overdose-death-rates. Updated January 2017. Accessed August 16, 2017

5. National Center for Health Statistics. Drug Overdose Deaths Among Adolescents Aged 15-19 in the United States: 1999-2015. NCHS Data Brief No. 282; August 2017.

6. Bonnie RJ, Kesselheim AS, Clark DJ. Both urgency and balance needed in addressing opioid epidemic: a report from the National Academies of Sciences, Engineering, and Medicine. JAMA. 2017; 318(5):423-424

7. US Centers for Disease Control and Prevention. HIV and Injection Drug Use. Atlanta, GA: CDC; 2016.

8. Murphy SM, Polsky D. Economic evaluations of opioid use disorder interventions. Pharmacoeconomics. 2016;34(9):863-887. 